Review

\title{
Novel Electrocardiographic Patterns for the Prediction of Hypertensive Disorders of Pregnancy_From Pathophysiology to Practical Implications
}

\section{Fabio Angeli ${ }^{1, *}$, Enrica Angeli ${ }^{2}$ and Paolo Verdecchia ${ }^{3}$}

1 Division of Cardiology and Cardiovascular Pathophysiology, Hospital "S.M. della Misericordia", Perugia 06100, Italy

2 Department of Obstetrics and Gynecology, Hospital "San Giovanni Battista", Foligno 06034, Italy; E-Mail: angeli.enrica@gmail.com

3 Department of Internal medicine, Hospital of Assisi, Assisi 06081, Italy; E-Mail: verdec@tin.it

* Author to whom correspondence should be addressed; E-Mail: angeli.internet@gmail.com; Tel.: +39-075-578-2394; Fax: +39-075-527-1509.

Academic Editor: Philip Newton Baker

Received: 26 April 2015 / Accepted: 31 July 2015 / Published: 7 August 2015

\begin{abstract}
Hypertensive disorders of pregnancy are a major cause of poor outcome, including placental abruption, organ failure, cerebrovascular accident and disseminated intravascular coagulation. These disorders are associated with increased fetal risk of intrauterine growth restriction, intrauterine death and prematurity. Electrocardiography (ECG) recently emerged as a useful tool to evaluate cardiovascular complications during pregnancy. Specifically, left atrial abnormalities detected by standard ECG are associated with a fourfold increased risk of developing hypertensive disorders during pregnancy. The mechanisms linking left atrial abnormality on ECG with hypertensive disorders are still elusive. Several mechanisms, possibly reflected by abnormal left atrial activation on ECG, has been suggested. These include increased reactivity to angiotensin II and up-regulation of angiotensin type 1 receptors, with activation of autoantibodies targeting these receptors.
\end{abstract}

Keywords: pregnancy; pregnancy; high-risk; eclampsia; pre-eclampsia; blood pressure; hypertension; pregnancy-induced; electrocardiography 


\section{Introduction}

Hypertension disorders complicate approximately $6 \%-11 \%$ of all pregnancies and remain leading causes of maternal and perinatal morbidity and mortality, particularly when elevated blood pressure (BP) is due to preeclampsia, either alone or superimposed on chronic vascular disease [1-3].

Specifically, they rank among the leading causes of maternal adverse outcome, along with embolism, hemorrhage and non-obstetric injuries, accounting for almost $15 \%$ of such deaths [2].

They also contribute significantly to stillbirths and fetal complications including abruptio placentae, intrauterine growth restriction, premature delivery, and intrauterine fetal death [4].

Hypertension in pregnancy is defined by office systolic BP $\geq 140 \mathrm{mmHg}$ and/or diastolic $\mathrm{BP} \geq 90 \mathrm{mmHg}$. According to current guidelines [5], hypertensive disorders during pregnancy are classified into four categories:

(i) Pre-existing or chronic hypertension (hypertension that was present before pregnancy or that develops at $<20$ th week gestation);

(ii) Gestational hypertension (hypertension that develops for the first time at $\geq 20$ th week' gestation; this definition is preferred over the older term of pregnancy-induced hypertension);

(iii) Preeclampsia-eclampsia;

(iv) Other hypertensive effects (including transient hypertensive effect, white-coat hypertensive effect and masked hypertensive effect).

For pre-existing and gestational hypertension, there are two subgroups: (1) with comorbid conditions that mandate tighter BP control as outside pregnancy (to protect end-organ function); and (2) with preeclampsia (given its substantial maternal and perinatal risks) [5].

Approximately $1 \%$ of pregnancies are complicated by pre-existing hypertension, $5 \%-6 \%$ by gestational hypertension, and $1 \%-2 \%$ by preeclampsia [5]. Nevertheless, rates of hypertensive disorders of pregnancy are anticipated to rise given older and more obese obstetric populations with more antecedent medical complications [5].

Epidemiological evidences supporting the worse prognosis associated with hypertension in pregnancy provide a strong basis for developing risk prediction models to identify women whose gestations may be considered at high risk for hypertensive disorders. These women may require a closer surveillance and preventive treatments [4].

Of note, of the many risk markers for hypertensive disorders [6-14], some are known at booking and increase the risk of hypertensive disorders two- to fourfold [15]. They include pre-existing hypertension, diabetes mellitus and renal disease, previous preeclampsia, antiphospholipid antibody syndrome, overweight/obesity, inter-pregnancy interval $\geq 10$ years, and multiple pregnancy $[15,16]$.

Just recently, the additive value of some instrumental techniques (including uterine artery Doppler velocimetry, electrocardiography [ECG] and ambulatory BP monitoring) and their combinations with maternal factors and biochemical markers to refine risk stratification for hypertensive disorders in pregnancy has also been evaluated [17-20]. In this context, some observations suggested that abnormal ECG patterns may increase the risk for hypertensive disorders of pregnancy [16,17,21]. 
We aimed to specifically address the evidence provided in this regard. We also critically discussed the available data supporting the concept that specific ECG patterns occurring in the first trimester of pregnancy may have clinical relevance for the risk prediction of hypertensive disorders.

For this purpose, we searched for clinical studies using research Methodology Filters [22,23]. The following research terms were used: "pregnancy", "pregnancy, high-risk", "eclampsia", "pre-eclampsia" "blood pressure", "hypertension, pregnancy-induced" and "electrocardiography". We also checked the reference list of identified articles and previous systematic reviews to find other relevant studies.

\section{Hemodynamic Changes in Pregnancy}

Knowledge of cardiovascular adaptations in pregnancy is required to correctly interpret ECG in the gravida, to predict the effects of pregnancy on the woman with underlying cardiac disease, and to understand how the fetus will be affected by maternal cardiac disorders.

The major hemodynamic changes induced by pregnancy include an increase in cardiac output (Figure 1), sodium and water retention leading to blood volume expansion, and reductions in systemic vascular resistance and systemic BP [24,25]. These changes begin early in pregnancy, reach their peak during the second trimester, and then remain relatively constant until delivery [24] (Figure 1). They contribute to optimal growth and development of the fetus and help to protect the mother from the risks of delivery, such as hemorrhage [24,25].
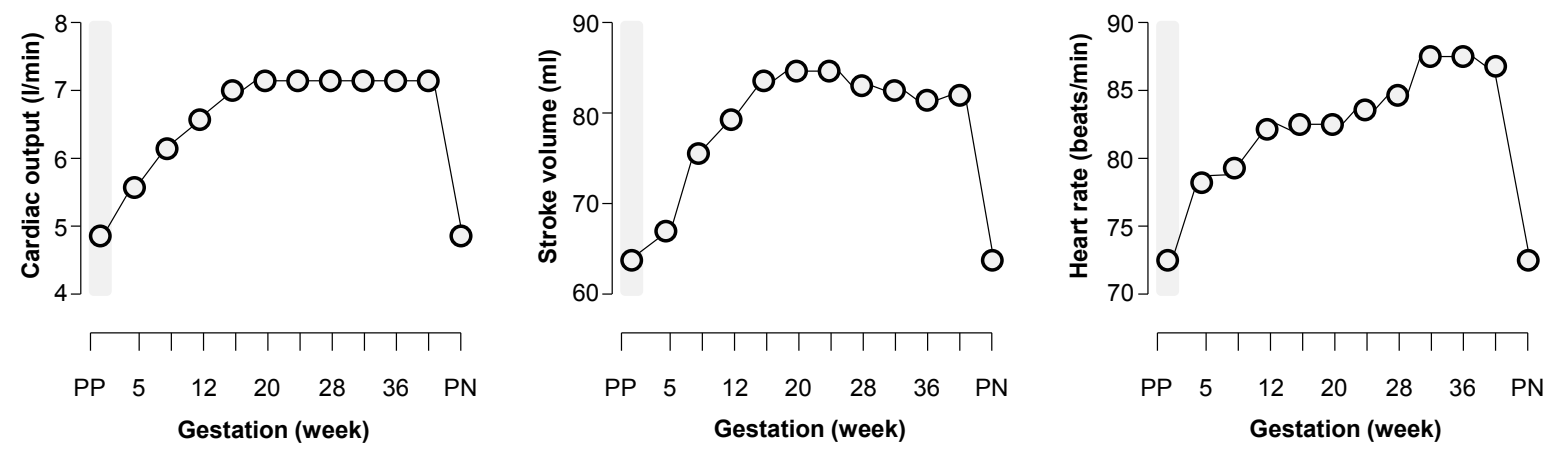

Figure 1. Changes in cardiac output from the non-pregnancy state throughout pregnancy. Related to the increase in plasma volume and vasodilation, cardiac output increases by $30 \%-50 \%$ during pregnancy via increases in both stroke volume and heart rate. $\mathrm{PP}=$ pre-pregnancy state; $\mathrm{PN}=$ post-natal state. Data from ref. [25].

Specifically, during pregnancy there is a $30 \%-50 \%$ increase in the extracellular fluid and a $30 \%-40 \%$ increase in plasma volume. The driving force for the increase in extracellular volume is decrease in the systemic vascular resistance, as reflected by a fall in the systolic and diastolic BP in early gestation [25].

Vasodilating factors such as nitric oxide (NO) play an important role in the decrease in vascular resistance [26]. The generalized vasodilation results in a compensatory activation of the renin-angiotensin-aldosterone system (RAAS), leading to water and sodium retention [27].

Furthermore, the renal blood flow and glomerular filtration rate markedly increase during pregnancy, and peak at approximately 50\% above non-pregnant levels in the second trimester [28].

Hemodynamic investigations in pregnant women with hypertensive disorders are scanty. Generally, in hypertensive disorders of pregnancy, the expansion of plasma volume and the decrease in vascular 
resistance are less pronounced [29]. As a direct consequence of the decreased plasma volume, cardiac output is also lower than in normal pregnancy [30]. Moreover, uterine and umbilical artery Doppler flow measurements have revealed that pregnancies complicated either by pre-eclampsia or growth restriction are characterized by a compromised uteroplacental flow, suggesting that the normally occurring expansion of plasma volume and increase in cardiac output are essential for the maintenance of a sufficient uteroplacental flow [29].

More recently, the picture has been complicated by different definitions and classifications of severe hypertensive disorders in pregnancy. Of note, different classifications of preeclampsia (mild, moderate and severe, as well as early and late) have been proposed [31,32].

Nevertheless, the concept of early (before 34 weeks) and late (after 34 weeks) preeclampsia is more modern and widely accepted for the evidence that these two entities probably recognize different etiologies and develop through different models of cardiovascular maternal adaptations [33-35]. Specifically, early preeclampsia, as a placenta-mediated disease [36,37], is commonly associated with abnormal uterine artery Doppler, fetal growth restriction, and adverse maternal and neonatal outcomes [33-35]. In contrast, late-onset preeclampsia is mostly associated with normal or slight increased uterine resistance index, a low rate of fetal involvement, and more favorable perinatal outcomes [33-35].

Maternal echocardiography may be useful to identify at 24 weeks of gestation women at increased risk of early complications through the evaluation of maternal hemodynamics and left ventricular geometry. High maternal total vascular resistance, increased relative wall thickness of the left ventricle, small left ventricular diameter and development of concentric left ventricular hypertrophy have been related to early-onset preeclampsia, suggesting an involvement of the whole cardiovascular system [38-40]. On the other hand, patients with late forms of preeclampsia showed low total vascular resistance, high cardiac output, increased diameter of the left ventricle with an intermediate relative wall thickness (eccentric geometry) as compared to controls and early preeclampsia [38-41].

\section{Pregnancy-Induced ECG Changes}

Pregnancy affects the ECG at some time point and there is restoration of these pregnancy-induced changes late in pregnancy or following delivery (Figure 2) [21,42-49].

Heart rate (HR) increases progressively throughout the pregnancy, reaching a peak during the third trimester. This increase in HR seems related to hormonal factors in early stages of pregnancy and later to increased left atrial diameter and sympathetic activation (sinus-node remodeling) [21]. Gestational age also impacts QRS complex and $T$-waves, promoting a leftward axis shift as pregnancy progresses. In particular, a leftward deviation of the mean QRS axis during the second and third trimesters of pregnancy and then rightward before delivery is observed in the majority of women [21,42-49]. PR interval exhibits a significant reduction in the mean values during pregnancy, while the QRS amplitude generally increases slightly in the late pregnancy (but without a clear evidence of left ventricular hypertrophy). No clinically significant changes occur in other ECG intervals (including QT interval) or cardiac rhythm (Figure 2) [21,42-49]. 
(A) Increase in heart rate
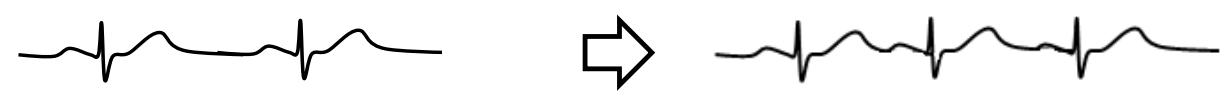

(B) Q wave in lead $D_{\text {III }}$
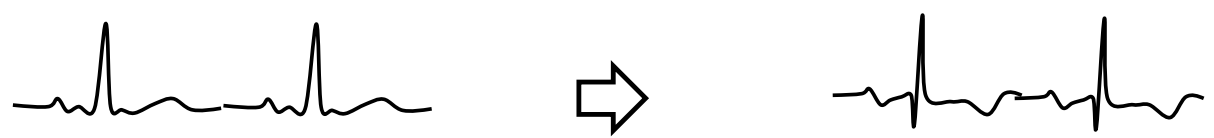

(C) Reduction in PR interval
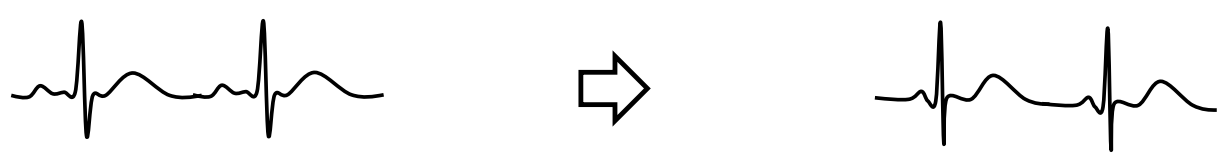

(D) Leftward deviation of the mean QRS axis
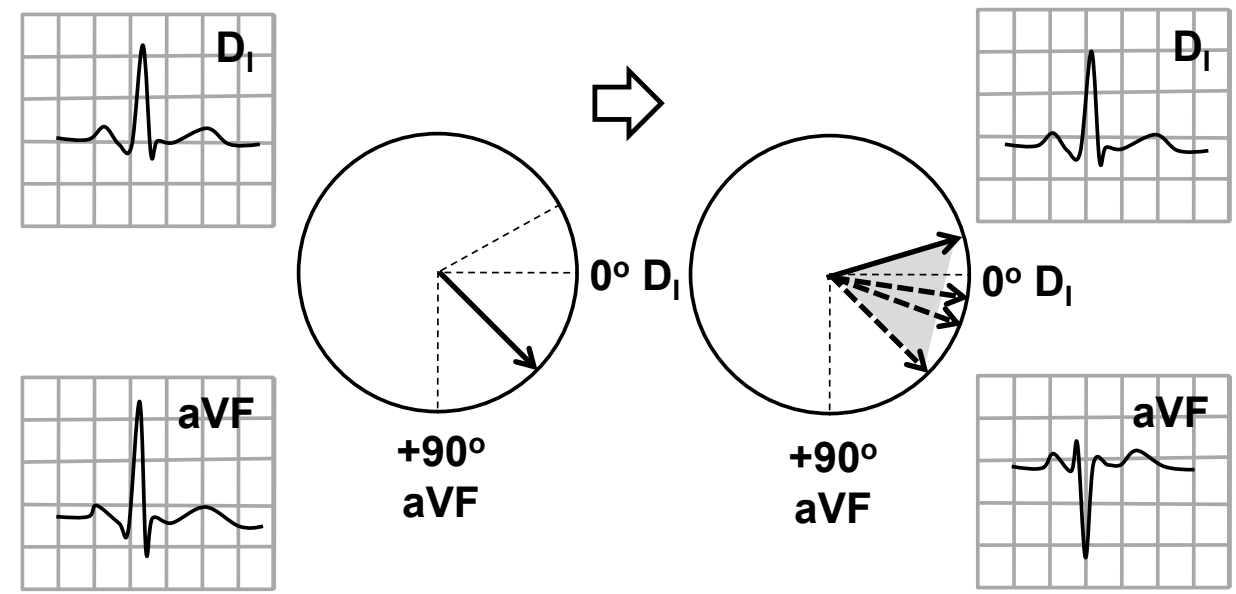

Figure 2. Normal electrocardiographic (ECG) adaptations during pregnancy. ECG changes in normal pregnancy include a reduction in the mean values of PR interval (C), sinus tachycardia (A), left axis deviation (D), inverted or flattened $T$-waves, and a $Q$-wave in lead DIII (B) [21].

\section{ECG Features of Increased Risk}

Only a few studies have investigated the ECG changes in pregnant women with hypertensive disorders during normal pregnancy [21]. Nevertheless, there is evidence that hypertensive disorders of pregnancy can be associated with changes in $P$-wave morphology and QT interval (Table 1) [21]. 
Table 1. Main clinical studies which demonstrated electrocardiographic features of increase risk for hypertensive disorders of pregnancy.

\begin{tabular}{ccccc}
\hline Study & {$[$ Ref.]/Year } & Design & Sample Size $(\boldsymbol{n})$ & ECG Features \\
\hline Isezuo and Ekele & {$[50] / 2004$} & Prospective & 60 & QT interval \\
Baumert et al. & {$[51] / 2010$} & Case-control & 64 & QT interval \\
Angeli et al. & {$[17] / 2011$} & Prospective & 221 & $P$-wave morphology \\
Raffaelli et al. & {$[52] / 2014$} & Case-control & 152 & QT interval, QT dispersion and $P$-wave duration \\
\hline
\end{tabular}

\subsection{QT Interval}

QT interval seems to be unaffected by normal pregnancy [42]. Conversely, pregnancies with abnormal uterine perfusion that developed pathological outcomes seem to be paralleled by changes in ventricular repolarization that may precede clinical symptoms [51].

In a recent study by Baumert and co-workers [51], monthly ECGs were recorded in 32 pregnant women with normal uterine perfusion and 32 pregnant women with abnormal perfusion, starting from the 20th week of gestation until 3 days postpartum. Among pregnancies with abnormal uterine perfusion, 17 pregnancies developed preeclampsia and/or small-for-gestational-age infants. While among patients with normal perfusion the QTc interval was unaltered, pregnancies with abnormal uterine perfusion that developed pathological outcomes showed a trend towards shorter QTc. Specifically, the QTc interval of women with pathological pregnancy outcomes appeared to shorten progressively throughout the second half of gestation, before the onset of clinical symptoms of hypertension or proteinuria [51].

More recently, Raffaelli and co-workers [52] investigated the effect of pre-eclampsia on electrical cardiac activity and demonstrated that pregnancies complicated by pre-eclampsia had a significant alteration of ventricular repolarization. They compared pre-partum ECGs of 76 consecutive pre-eclamptic women with those of 76 healthy pregnant women. All of the routine ECG parameters were considered, and ventricular repolarization was assessed by QT interval and QT dispersion (QTd).

The routine evaluation of the ECGs in both groups was mostly non-pathological. However, pre-eclamptic women showed a lower HR $(77.4 \pm 14.3$ vs. $81.6 \pm 11.0$ beats per minute $[\mathrm{bpm}])$, a longer mean QTc interval $(442.7 \pm 26.7 v s .423 .7 \pm 20.7 \mathrm{~ms})$ and a higher QTd $(24.0 v s .22 .0 \mathrm{~ms})$ than the control group [52].

In this context, it is worthy to be mentioned that QTd is an indicator of inhomogeneity in ventricular activity and its prolongation is correlated with an increased incidence of ventricular arrhythmias and is a predictor of all-cause mortality [53]. Thus, prolonged QT dispersion could explain the increased incidence of serious ventricular arrhythmias and adverse outcomes in pregnant women with pre-eclampsia [52].

Similarly, in a prospective study by Isezuo and Ekele [50], eclampsia was associated with prolonged ventricular repolarization. Briefly, the QT interval corrected for HR, serum calcium, magnesium and potassium were compared among 30 intrapartum eclamptics and 30 age, parity and gestational age-matched women with uncomplicated pregnancy. HR ranged from 76 to $163 \mathrm{bpm}$ and 65 to $112 \mathrm{bpm}$ among patients and controls, respectively. The corresponding QTc were 390-572 ms and 390-460 ms, respectively. Compared to the controls, the eclamptic patients had higher frequency of abnormal QTc (46.7\% vs. 6.6\%, odds ratio [OR]: 9.2; 95\% confidence interval [CI]: 1.61-68.48, $p=0.01)$ as measured on the surface ECG [50]. 


\subsection{Abnormal P-Wave Morphology}

Studies by the group above [52] and our [16,17] investigated abnormal $P$-wave morphology during pregnancy as potential predictor of hypertensive disorders during pregnancy.

In the recent analysis by Raffaelli et al. [52], $P$-wave duration was significantly longer in the pre-eclamptic women than in the control group of normal pregnancy [52].

Furthermore, a prospective collaborative screening study between gynecologists, internists and cardiologists evaluated the potential additive role of standard ECG in the identification of women at increased risk for hypertensive complications [17].

At the first antenatal visit, 12-lead ECG was recorded and the following ECG parameters were analyzed (Figure 3): HR, QRS duration, QTc interval, Cornell voltage, ST-T abnormalities, and left atrial abnormality.

The QT interval was measured as the time between the start of the $Q$-wave and the end of the $T$-wave and corrected by HR according to the Bazett's formula [54].

The Cornell voltage was computed as the sum of the amplitudes of $S$-wave in $\mathrm{V}_{3}$ and $R$-wave in aVL [55].

ST-T changes were analyzed according to the Minnesota Coding [56]. Criteria for ST-T changes were any of the following: (1) coexistence, in any leads I, II, aVL or V3-V6 of ST-segment horizontal or downward sloping depression $\geq 0.05 \mathrm{mV}$ (code 4-1 or 4-2) plus $T$-wave asymmetric inversion (code 5-1 or 5-2); (2) ST-J depression $<0.05 \mathrm{mV}$ with ST-segment downward sloping and segment or $T$-wave nadir $>0.05 \mathrm{mV}$ below P-R baseline, in any of leads I, II, aVL or V2-V6 (code 4-3); (3) ST-J depression of $\geq 0.10 \mathrm{mV}$ and ST-segment upward sloping or $U$-shaped, in any of leads I, II, aVL or V2-V6 (code 4-4); (4) T-wave amplitude zero (flat), negative or diphasic (negative-positive type only) with $<0.10 \mathrm{mV}$ negative phase in lead I, II, V3-V6, or in lead aVL when $R$-wave amplitude is $\geq 0.5 \mathrm{mV}$ (code 5-3); (5) $T$-wave amplitude positive and $T$ - to $R$-wave amplitude ratio $<1: 20$ in any of leads I, II, aVL or V3-V6 when $R$-wave amplitude in the corresponding leads is $\geq 1.0 \mathrm{mV}$ (code 5-4).

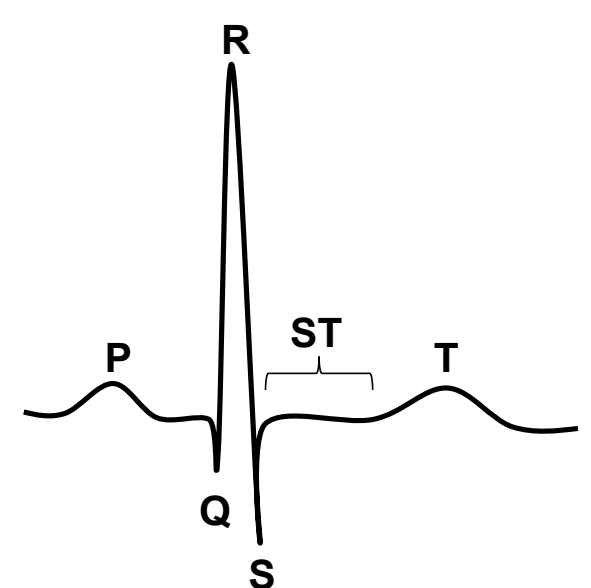

S

QRS
P wave

- Indicates atrial depolarization

QRS complex

- Indicates ventricular depolarization

T wave

- Indicates ventricular repolarization

ST segment

- Indicates early ventricular repolarization

QT interval

- Represents ventricular depolarization and repolarization

Figure 3. ECG components and intervals tested as predictors of hypertensive disorders of pregnancy in nulliparous healthy women with singleton pregnancies. 
$P$-wave morphology was analyzed in all of the standard leads. The criteria used for the diagnosis of $P$-wave abnormality in lead $\mathrm{V}_{1}$ were: (1) bipeak interval in deeply notched $P$-wave with (2) terminal forces equal to or more negative than $-0.04 \mathrm{~mm} \cdot \mathrm{s}$, as obtained from the product of the depth of the terminal negative deflection and its duration [57,58]. The following other criteria were used for the diagnosis of LA abnormality in any other lead than $\mathrm{V}_{1}$ : (1) bipeak interval in deeply notched $P$-waves wider than $0.04 \mathrm{~s}$; or (2) $P$-wave/PR-segment ratio greater than 1.6 ; or (3) $P$-wave higher than $3 \mathrm{~mm}$; or (4) total $P$-wave duration greater than $0.11 \mathrm{~s}[57,58]$.

The primary outcome of the study was the development of gestational hypertension, pre-eclampsia and eclampsia. The secondary outcome was a composite measure of hypertensive disorders and other pregnancy complications including fetal growth restriction, HELLP (hemolysis, elevated liver enzymes, low platelets) syndrome, placental abruption, stillbirth, premature delivery and neonatal death $[4,59,60]$.

Overall, 308 women were screened and 87 excluded. Thus, a total of 221 pregnant women were included in the final analysis [17].

The primary outcome of hypertensive disorders occurred in 28 women. Specifically, gestational hypertension occurred in 22 women, 5 women experienced pre-eclampsia ( 3 of these developed HELLP syndrome) and 1 woman had eclampsia. Among pre-eclamptic women, 3 had late-onset pre-eclampsia ( $\geq 34$ weeks gestation).

The secondary composite outcome was recorded in 43 women. Multiple events (hypertensive disorders and other maternal or fetal/neonatal complications) were observed in 9 women.

Overall, premature deliveries occurred in 14 women, 6 women delivered growth-restricted neonates, 2 women experienced placental abruption and 2 congenital heart defect requiring admission to neonatal nursery were recorded. No neonatal deaths were observed.

Study population was sub-divided into two groups by occurrence of hypertensive disorders during pregnancy. At entry, women with development of hypertensive disorders differed under some aspects from those who did not experience these events: Weight, body mass index (BMI) and BP were higher in women with hypertensive diseases than in those without (all $p<0.05$ ).

Left atrial abnormality in lead $\mathrm{V}_{1}$ was also more prevalent in women with hypertension disorders $(p=0.002)$. Age, laboratory tests, HR and other ECG parameters including left atrial abnormality observed in other leads than $\mathrm{V}_{1}$ did not differ between the two groups.

In a multivariable model, mean arterial pressure (MAP) and left atrial abnormality in lead $\mathrm{V}_{1}$ were independent predictors of hypertensive disorders.

In particular, the presence of LA abnormality in lead $\mathrm{V}_{1}$ was associated to a 4-fold increased risk of developing hypertensive disorders (OR: 4.35; 95\% CI: $1.84-10.31 ; p=0.001$ ).

The final predictive model discriminated well between women who developed hypertensive disorders and women who remained normotensive during pregnancy, with an area under the curve of 0.754 (95\% CI: $0.667-0.841, p<0.0001)$.

The probability of developing hypertensive disorders according to baseline MAP and $P$-wave morphology (normal vs left atrial abnormality in lead $\mathrm{V}_{1}$ ) is depicted in Figure 4.

Although the primary outcome of the study was the development of hypertensive disorders, the same prediction model also proved significance to identify pregnant women at increased risk for the occurrence of maternal and fetal/neonatal complications [17]. 


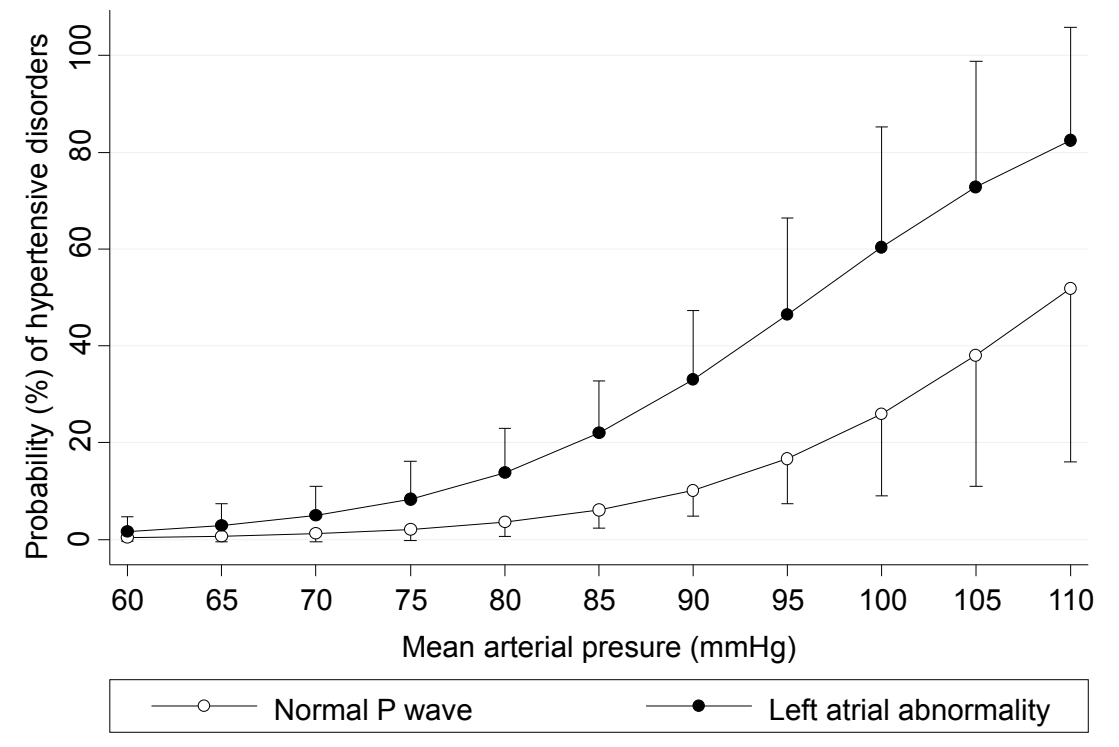

Figure 4. Risk of developing hypertensive disorders (probability with 95\% confidence intervals) according to baseline mean arterial pressure and $P$-wave morphology in lead $\mathrm{V}_{1}$.

\section{P-Wave Morphology and Risk of Hypertensive Disorders: Mechanisms}

Abnormality of $P$-wave morphology in lead $\mathrm{V}_{1}$ tested as predictor of hypertensive disorders during pregnancy [17] is commonly used as an ECG sign of left atrial enlargement and it may be easily diagnosed by traditional visual interpretation of ECG tracings, without any need of digitalization or other computer facilities [16].

Left atrial enlargement is very common in hypertensive subjects and may be an early sign of heart involvement in arterial systemic hypertension [61,62].

In this context, some echocardiographic studies showed that women developing hypertensive complications during pregnancy may have different echocardiographic patterns than controls $[38,40,41,63]$.

Nevertheless, the potential link between left atrial abnormality detected early in pregnancy by echocardiography or ECG and development of hypertensive disorders remains elusive.

Some possible mechanisms are supported by epidemiological data and experimental models [16,17,21]. As depicted in Figure 5, they include hemodynamic and molecular mechanisms.

\subsection{Hemodynamic Mechanisms}

Many clinical studies in hypertensive patients found a significant relation between BP overload and left atrial abnormalities [61,62,64-66]. The lack of association between left atrial enlargement at ECG and BP values observed in our study [17] supports the poor ability of casual BP measurements obtained at the time of the first visit to the hospital to detect the real BP load of pregnant women. In other words, the tendency of BP to decrease in early pregnancy [67] may mask the real load of women with abnormal BP before pregnancy. Thus, the presence of an abnormal $P$-wave in the early phase of gestation may be considered as a marker of masked hypertension or high or high-normal BP values. 


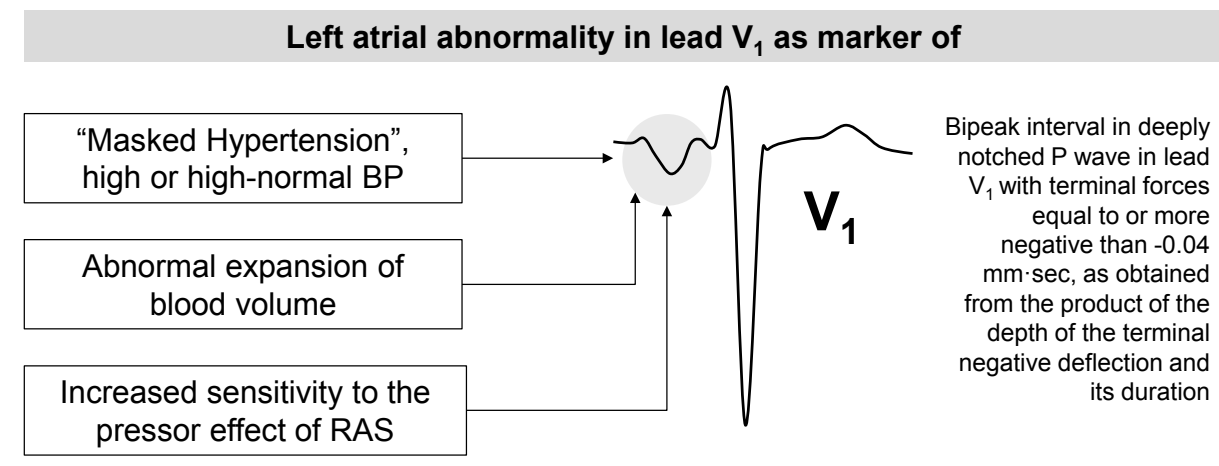

Figure 5. Potential mechanisms linking left atrial abnormality detected early in pregnancy by ECG and development of hypertensive disorders during pregnancy. Data from ref. [16,17,21].

Expansion of blood volume directly affects left atrial pressure and dimensions [68] with a consequent increased release of atrial natriuretic peptide (ANP) [69]. As described above, the major hemodynamic changes during pregnancy include an increase in cardiac output, sodium and water retention leading to blood volume expansion. These changes begin early in pregnancy, reach their peak during the second trimester and then remain relatively constant until delivery [70,71]. In uncomplicated pregnancy, plasma renin activity tends to be increased and ANP levels are slightly reduced [72,73]. In contrast, plasma ANP concentrations have been extensively reported as increased in patients with hypertensive disorders during pregnancy, especially in patients with severe pre-eclampsia [74-76]. The detection of left atrial enlargement may be a marker of an abnormal expansion of blood volume in the early phase of pregnancy which may affect left atrial morphology [68] and the possible consequent increased release of ANP may predispose to the development of hypertensive disease.

Moreover, left ventricular hypertrophy has been suggested to mediate, at least partially, the relation between hypertension and left atrial enlargement [77].

The presence of abnormal $P$-wave morphology at ECG may be a marker of "latent" abnormal left ventricular mass (hypertrophized ventricle) which commonly develop in both early and late onset preeclampsia (as manifestation of an underfilling state with pressure overload and an overfilling state without pressure overload, respectively) [38-41].

Nevertheless, echocardiographic data on the relationship between the simultaneous adaptations of left ventricle and left atrium during hypertensive disorders of pregnancy are scarce and conflicting [78-80]. In a recent case-control study involving 37 pregnant women (20 with pre-eclampsia and 17 age-matched controls), ventricular septal thickness, posterior wall thickness, and left ventricular mass index were significantly greater in patients with preeclampsia than in controls $(p<0.0001)$ [80]. Nevertheless, there were no significant differences in left atrial diameter [78]. Similar results were also obtained by Borghi et al. [79] in a sample of 75 pregnant women. Conversely, Vazquez et al. failed to demonstrate changes of both left ventricle and left atrium in women with preeclampsia [80].

Finally, it is worthy to be mentioned that diastolic dysfunction contributes to left atrial remodeling and that atrial enlargement has been suggested as a marker of the severity and duration of diastolic dysfunction [81]. Diastolic cardiac function varies during pregnancy. A relationship between preload, afterload, morphologic, and diastolic function modifications appears to exist as a consequence of the hemodynamic modifications which occur during physiologic pregnancy [82]. Diastolic function 
analysis may be useful to identify women who fully adapt to pregnancy, and to understand the mechanisms that might be involved in pregnant women who develop hypertensive disorders [82].

Of note, a prospective study including 1688 high risk nulliparous women demonstrated that diastolic function differs among women with preeclampsia and controls [41].

In particular, some Doppler values (E/A ratio and $A$-wave velocity) suggested a more altered diastole in both early and late preeclampsia compared to controls 1 year postpartum [41].

\subsection{Molecular Mechanisms}

Other changes during pregnancy include a marked stimulation of the all measured elements of the RAAS [60,83-85] (Figure 6). There is an early increase in renin due to extra-renal local release by the ovaries and maternal decidua [83-85]. Angiotensinogen synthesis by the liver is increased by circulating estrogen produced by the growing placenta [83-85]. This leads to increased serum Angiotensin II and aldosterone levels [83-85].

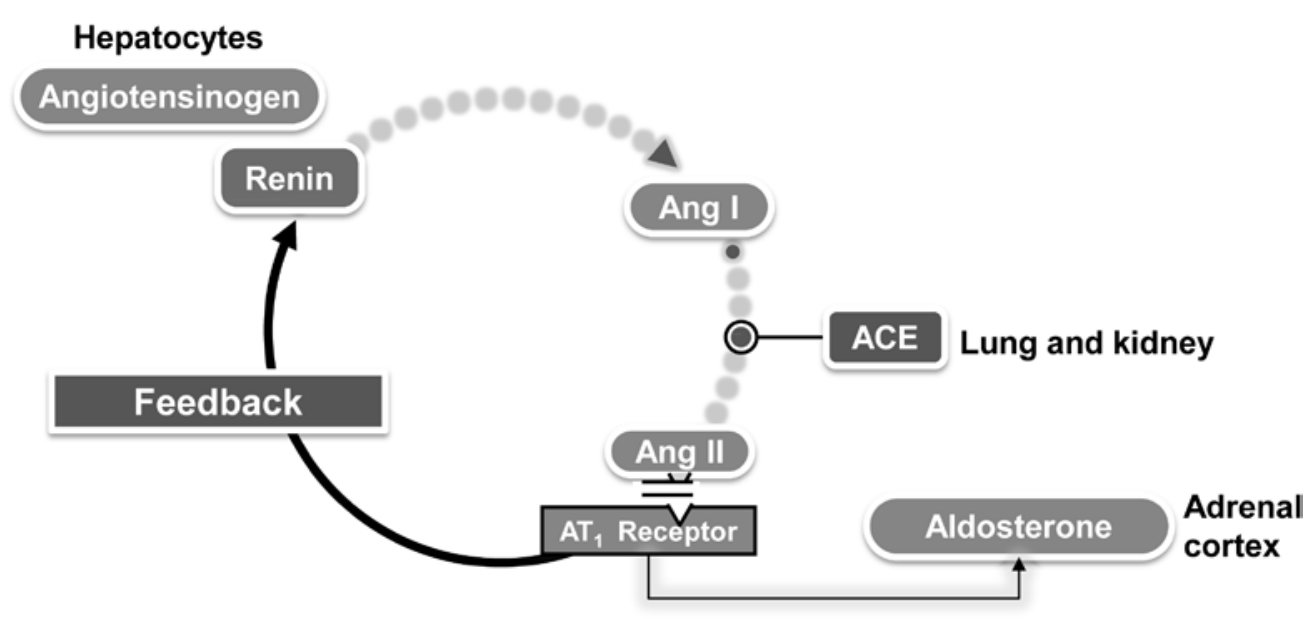

Figure 6. Schematic of the classic RAAS system cascade. The biosynthesis of renin by the juxtaglomerular cells is a key determinant of the activity of the RAS. Renin regulates the initial, rate-limiting step of the RAS by cleaving the $N$-terminal portion of a large molecular weight globulin, angiotensinogen, to form the biologically inert decapeptide Angiotensin I or Angiotensin-(1-10). The inactive decapeptide Angiotensin I is hydrolyzed by angiotensin-converting enzyme (ACE), which removes the $C$-terminal dipeptide to form the octapeptide Angiotensin II [Ang-(1-8)], a biologically active, potent vasoconstrictor.

Although Angiotensin II levels increase during pregnancy, normotensive pregnant women are actually refractory to its vasopressor effects.

Assali et al. [86] demonstrated that the pregnant woman requires twice as much Angiotensin II intravenous infusion over a non-pregnant woman to achieve the same vasomotor response. This is thought to be due to the presence of increased progesterone and prostacyclins which can decrease Angiotensin II sensitivity [87].

Additionally, in normal pregnancy Angiotensin Type $1\left(\mathrm{AT}_{1}\right)$ receptors are monomeric and are inactivated by reactive oxygen species (ROS). This is in comparison to the heterodimeric state seen in Angiotensin II sensitive conditions [88]. 
Taken together, these observations help explain why a greater Angiotensin II stimulus is required in order to achieve the appropriate vasomotor response in normotensive pregnancies.

Conversely, in preeclamptic women the circulating levels of renin, Angiotensin I and aldosterone are lower than their normotensive counterparts [85]. There are two exceptions to the decreases observed. The ACE level is approximately the same and Angiotensin 1-7, a vasodilatory member of the RAAS, is significantly reduced in preeclampsia [85].

Moreover, in pregnant women developing severe forms of hypertensive disorders there is a loss of the normal pregnancy-associated refractoriness to pressor agents and the sensitivity to infused Angiotensin II increases weeks before overt disease [89-97].

Explanations for the increased reactivity to Angiotensin II include up-regulation of receptor sensitivity, synergy with circulating autoantibodies agonistic to the $\mathrm{AT}_{1}$ receptor and decreases in the level of circulating Angiotensin 1-7 [89-97].

Experimental studies have shown that the RAAS in the heart could trigger cardiac hypertrophy [98] and a massive enlargement of the atria caused by myocyte hyperplasia [99]. Thus, an increased sensitivity to the pressor effect of the Angiotensin II in some women may be involved in the development of ECG signs of left atrial enlargement and may predispose to the development of hypertensive disorders [16,17,21] (Figure 7).

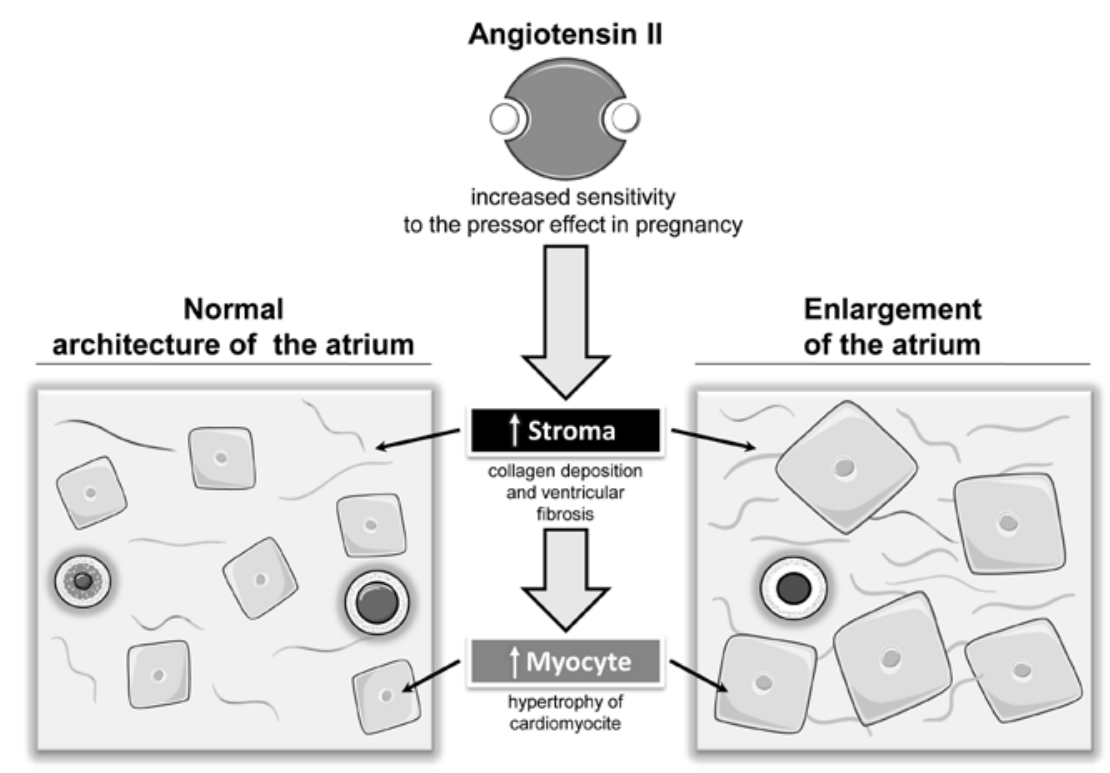

Figure 7. Effects on left atrium of Angiotensin II in pregnancy complicated by hypertensive disorder.

\section{Conclusions and Perspectives}

Several risk factors have been proposed as potential predictors of hypertensive disorders during pregnancy [11]. They include maternal demographics and clinical characteristics [15], laboratory markers (plaminogen activator inhibitor, placental growth factor, von Willerand factor, $C$-reactive protein and serum uric acid), provocative biophysical tests (angiotensin II challenge test, roll-over test, isometric exercise test), urinary proteomics, inherited thrombophilias (factor V Leiden mutation, prothrombin gene mutation, protein $\mathrm{C}$ or $\mathrm{S}$ deficiency and antithrombin III deficiency), 
antiphospholipid antibodies and abnormal maternal serum markers (alpha fetoprotein, human chorionic gonadotrophin and plasma tumor necrosis factor alpha) [100-108].

Nevertheless, early prediction of hypertensive disorders in healthy and initially normotensive pregnant women remains problematic, partly because severe forms such as preeclampsia and eclampsia are etiologically complex and heterogeneous conditions [16].

No guidelines exist for an appropriate and cost-effectiveness screening and early detection of hypertensive disorders in the community and there is no uniformity in referral thresholds and assessment procedures. In addition, systematic reviews suggest that any single test may lack predictive value or practical utility to be applied at large [100-102].

In the last few years, some clinical studies tested the combinations of different risk markers to develop multivariable models for the prediction of hypertensive disorders during pregnancy [8,15-17]. The use of multiple markers in a screening approach may reflects different aspects of the hypertensive disease process and increases the specificity and sensitivity of the screening [17].

In this context, some studies analyzed the additive value of ECG and its combination with maternal factors and biochemical markers to refine risk stratification for hypertensive disorders in pregnancy [8,15-17].

In particular, changes during pregnancy in QT interval and $P$-wave morphology have been tested as potential features of increased risk for the development of hypertensive disorders.

With regard to QT interval changes and its time course during gestation, clinical studies have produced conflicting results and it is not clear whether alterations in the QT interval precede clinical manifestations of hypertensive disorders [50-52].

Moreover, as documented by the analysis by Raffaelli and co-workers [52], the prolonged QTc interval observed in the acute phase of hypertensive disorders of pregnancy might be only the result of high-dose administration of $\mathrm{MgSO}_{4}$. Thus, in our opinion the notion that increased ventricular repolarization heterogeneity (as documented by higher values of QTd) is a spontaneous high-risk feature of pre-eclampsia for the development of adverse events remains questionable [21].

More interestingly, a recent prospective screening study in nulliparous healthy women with singleton pregnancies showed that combination of left atrial enlargement at ECG and BP measurement improves the accuracy of risk models for the prediction of hypertensive disorders of pregnancy, especially for the more severe forms [17].

In conclusion, there is no single screening test that may be definitely assumed as reliable and cost-effective for the prediction of hypertensive disorders in pregnancy. Most of the tested markers suffer from poor sensitivity and poor positive predictive values, and the majority of them are not suitable for routine use in clinical practice [16].

However, recent studies have generated the hope that combining new screening tests with risk markers will provide the sensitivities and likelihood ratios required for prediction of hypertensive disorders in pregnancy enhancing the ability of clinicians to detect subgroups of pregnant women at increased risk.

\section{Acknowledgments}

This study was funded in part by the Fondazione Umbra Cuore e Ipertensione-ONLUS, Perugia, Italy. 


\section{Conflicts of Interest}

The authors declare no conflict of interest.

\section{References}

1. Berg, C.J.; Chang, J.; Callaghan, W.M.; Whitehead, S.J. Pregnancy-related mortality in the United States, 1991-1997. Obstet. Gynecol. 2003, 101, 289-296.

2. Chang, J.; Elam-Evans, L.D.; Berg, C.J.; Herndon, J.; Flowers, L.; Seed, K.A.; Syverson, C.J. Pregnancy-related mortality surveillance-United States, 1991-1999. MMWR Surveill. Summ. 2003, 52, 1-8.

3. MacKay, A.P.; Berg, C.J.; Duran, C.; Chang, J.; Rosenberg, H. An assessment of pregnancy-related mortality in the United States. Paediatr. Perinat. Epidemiol. 2005, 19, 206-214.

4. Program, National High Blood Pressure Education. Report of the national high blood pressure education program working group on high blood pressure in pregnancy. Am. J. Obstet. Gynecol. 2000, 183, S1-S22.

5. Magee, L.A.; Pels, A.; Helewa, M.; Rey, E.; von Dadelszen, P.; Hypertension Guideline, C.; Magee, L.A.; Audibert, F.; Bujold, E.; Cote, A.M.; et al. Diagnosis, evaluation, and management of the hypertensive disorders of pregnancy: Executive summary. J. Obstet. Gynaecol. Can. 2014, $36,416-438$.

6. Audibert, F.; Benchimol, Y.; Benattar, C.; Champagne, C.; Frydman, R. Prediction of preeclampsia or intrauterine growth restriction by second trimester serum screening and uterine doppler velocimetry. Fetal Diagn. Ther. 2005, 20, 48-53.

7. Dugoff, L.; Hobbins, J.C.; Malone, F.D.; Porter, T.F.; Luthy, D.; Comstock, C.H.; Hankins, G.; Berkowitz, R.L.; Merkatz, I.; Craigo, S.D.; et al. First-trimester maternal serum papp-a and free-beta subunit human chorionic gonadotropin concentrations and nuchal translucency are associated with obstetric complications: A population-based screening study (the faster trial). Am. J. Obstet. Gynecol. 2004, 191, 1446-1451.

8. Halligan, A.; Bonnar, J.; Sheppard, B.; Darling, M.; Walshe, J. Haemostatic, fibrinolytic and endothelial variables in normal pregnancies and pre-eclampsia. Br. J. Obstet. Gynaecol. 1994, 101, 488-492.

9. Hershkovitz, R.; de Swiet, M.; Kingdom, J. Mid-trimester placentation assessment in high-risk pregnancies using maternal serum screening and uterine artery doppler. Hypertens. Pregnancy 2005, 24, 273-280.

10. Kurdi, W.; Campbell, S.; Aquilina, J.; England, P.; Harrington, K. The role of color doppler imaging of the uterine arteries at 20 weeks' gestation in stratifying antenatal care. Ultrasound Obstet. Gynecol. 1998, 12, 339-345.

11. Milne, F.; Redman, C.; Walker, J.; Baker, P.; Bradley, J.; Cooper, C.; de Swiet, M.; Fletcher, G.; Jokinen, M.; Murphy, D.; et al. The pre-eclampsia community guideline (precog): How to screen for and detect onset of pre-eclampsia in the community. BMJ 2005, 330, 576-580. 
12. Salomon, O.; Seligsohn, U.; Steinberg, D.M.; Zalel, Y.; Lerner, A.; Rosenberg, N.; Pshithizki, M.; Oren, M.; Ravid, B.; Davidson, J.; et al. The common prothrombotic factors in nulliparous women do not compromise blood flow in the feto-maternal circulation and are not associated with preeclampsia or intrauterine growth restriction. Am. J. Obstet. Gynecol. 2004, 191, 2002-2009.

13. Steegers-Theunissen, R.P.; van Iersel, C.A.; Peer, P.G.; Nelen, W.L.; Steegers, E.A. Hyperhomocysteinemia, pregnancy complications, and the timing of investigation. Obstet. Gynecol. 2004, 104, 336-343.

14. Yu, C.K.; Smith, G.C.; Papageorghiou, A.T.; Cacho, A.M.; Nicolaides, K.H. An integrated model for the prediction of preeclampsia using maternal factors and uterine artery doppler velocimetry in unselected low-risk women. Am. J. Obstet. Gynecol. 2005, 193, 429-436.

15. Duckitt, K.; Harrington, D. Risk factors for pre-eclampsia at antenatal booking: Systematic review of controlled studies. BMJ 2005, 330, 565, doi:10.1136/bmj.38380.674340.

16. Angeli, F.; Angeli, E.; Reboldi, G.; Verdecchia, P. Hypertensive disorders during pregnancy: Clinical applicability of risk prediction models. J. Hypertens. 2011, 29, 2320-2323.

17. Angeli, E.; Verdecchia, P.; Narducci, P.; Angeli, F. Additive value of standard ecg for the risk prediction of hypertensive disorders during pregnancy. Hypertens. Res. 2011, 34, 707-713.

18. Benedetto, C.; Valensise, H.; Marozio, L.; Giarola, M.; Massobrio, M.; Romanini, C. A two-stage screening test for pregnancy-induced hypertension and preeclampsia. Obstet. Gynecol. 1998, 92, 1005-1011.

19. Giguere, Y.; Charland, M.; Bujold, E.; Bernard, N.; Grenier, S.; Rousseau, F.; Lafond, J.; Legare, F.; Forest, J.C. Combining biochemical and ultrasonographic markers in predicting preeclampsia: A systematic review. Clin. Chem. 2010, 56, 361-375.

20. Poon, L.C.; Kametas, N.A.; Maiz, N.; Akolekar, R.; Nicolaides, K.H. First-trimester prediction of hypertensive disorders in pregnancy. Hypertension 2009, 53, 812-818.

21. Angeli, F.; Angeli, E.; Verdecchia, P. Electrocardiographic changes in hypertensive disorders of pregnancy. Hypertens. Res. 2014, 37, 973-975.

22. Haynes, R.B.; Kastner, M.; Wilczynski, N.L.; Hedges, T. Developing optimal search strategies for detecting clinically sound and relevant causation studies in embase. BMC Med. Inform. Decis. Mak. 2005, 5, 8, doi:10.1186/1472-6947-5-8.

23. Haynes, R.B.; Wilczynski, N.; McKibbon, K.A.; Walker, C.J.; Sinclair, J.C. Developing optimal search strategies for detecting clinically sound studies in medline. J. Am. Med. Inform. Assoc. 1994, 1, 447-458.

24. Chapman, A.B.; Abraham, W.T.; Zamudio, S.; Coffin, C.; Merouani, A.; Young, D.; Johnson, A.; Osorio, F.; Goldberg, C.; Moore, L.G.; et al. Temporal relationships between hormonal and hemodynamic changes in early human pregnancy. Kidney Int. 1998, 54, 2056-2063.

25. Hunter, S.; Robson, S.C. Adaptation of the maternal heart in pregnancy. Br. Heart J. 1992, $68,540-543$.

26. Williams, D.J.; Vallance, P.J.; Neild, G.H.; Spencer, J.A.; Imms, F.J. Nitric oxide-mediated vasodilation in human pregnancy. Am. J. Physiol. 1997, 272, H748-H752.

27. Brown, M.A.; Gallery, E.D. Volume homeostasis in normal pregnancy and pre-eclampsia: Physiology and clinical implications. Baillieres Clin. Obstet. Gynaecol. 1994, 8, 287-310. 
28. Moran, P.; Lindheimer, M.D.; Davison, J.M. The renal response to preeclampsia. Semin. Nephrol. 2004, 24, 588-595.

29. Salas, S.P.; Marshall, G.; Gutierrez, B.L.; Rosso, P. Time course of maternal plasma volume and hormonal changes in women with preeclampsia or fetal growth restriction. Hypertension 2006, 47, 203-208.

30. Visser, W.; Wallenburg, H.C. Central hemodynamic observations in untreated preeclamptic patients. Hypertension 1991, 17, 1072-1077.

31. Huppertz, B. Placental origins of preeclampsia: Challenging the current hypothesis. Hypertension 2008, 51, 970-975.

32. Von Dadelszen, P.; Magee, L.A.; Roberts, J.M. Subclassification of preeclampsia. Hypertens. Pregnancy 2003, 22, 143-148.

33. Murphy, D.J.; Stirrat, G.M. Mortality and morbidity associated with early-onset preeclampsia. Hypertens. Pregnancy 2000, 19, 221-231.

34. Ness, R.B.; Sibai, B.M. Shared and disparate components of the pathophysiologies of fetal growth restriction and preeclampsia. Am. J. Obstet. Gynecol. 2006, 195, 40-49.

35. Sibai, B.; Dekker, G.; Kupferminc, M. Pre-eclampsia. Lancet 2005, 365, 785-799.

36. Crispi, F.; Dominguez, C.; Llurba, E.; Martin-Gallan, P.; Cabero, L.; Gratacos, E. Placental angiogenic growth factors and uterine artery doppler findings for characterization of different subsets in preeclampsia and in isolated intrauterine growth restriction. Am. J. Obstet. Gynecol. 2006, 195, 201-207.

37. Crispi, F.; Llurba, E.; Dominguez, C.; Martin-Gallan, P.; Cabero, L.; Gratacos, E. Predictive value of angiogenic factors and uterine artery doppler for early- vs. late-onset pre-eclampsia and intrauterine growth restriction. Ultrasound Obstet. Gynecol. 2008, 31, 303-309.

38. Novelli, G.P.; Valensise, H.; Vasapollo, B.; Larciprete, G.; Altomare, F.; di Pierro, G.; Casalino, B.; Galante, A.; Arduini, D. Left ventricular concentric geometry as a risk factor in gestational hypertension. Hypertension 2003, 41, 469-475.

39. Valensise, H.; Vasapollo, B.; Novelli, G.P.; Pasqualetti, P.; Galante, A.; Arduini, D. Maternal total vascular resistance and concentric geometry: A key to identify uncomplicated gestational hypertension. BJOG 2006, 113, 1044-1052.

40. Vasapollo, B.; Novelli, G.P.; Valensise, H. Total vascular resistance and left ventricular morphology as screening tools for complications in pregnancy. Hypertension 2008, 51, 1020-1026.

41. Valensise, H.; Vasapollo, B.; Gagliardi, G.; Novelli, G.P. Early and late preeclampsia: Two different maternal hemodynamic states in the latent phase of the disease. Hypertension 2008, 52, 873-880.

42. Carruth, J.E.; Mivis, S.B.; Brogan, D.R.; Wenger, N.K. The electrocardiogram in normal pregnancy. Am. Heart J. 1981, 102, 1075-1078.

43. Akinwusi, P.O.; Oboro, V.O.; Adebayo, R.A.; Akintunde, A.A.; Adeniji, A.O.; Isawumi, I.A.; Balogun, M.O.; Ogungbamigbe, T.O. Cardiovascular and electrocardiographic changes in nigerians with a normal pregnancy. Cardiovasc. J. Afr. 2011, 22, 71-75.

44. Boyle, D.M.; Lloyd-Jones, R.L. The electrocardiographic st segment in pregnancy. J. Obstet. Gynaecol. Br. Commonw. 1966, 73, 986-987. 
45. Grand, A.; Rigaud-Morel, N.; Drouin, B.; Boissel, J.; Burel, H. Electrocardiographic changes induced by pregnancy in healthy women. Arch. Mal. Coeur. Vaiss. 1983, 76, 77-86.

46. Gregorini, L.; Valentini, R.; lo Cicero, G.; Ferrari, A.; Mancia, G. Electrocardiographic and vectorcardiographic modifications during pregnancy and post partum. Boll. Soc. Ital. Cardiol. 1976, 21, 2049-2054.

47. Halphen, C.; Leguludec, D.; Valent, R.; Haiat, R. Electrocardiographic study of left ventricular performance in normal pregnancy. Arch. Mal. Coeur. Vaiss. 1984, 77, 212-217.

48. Illanes, A.; Droguett, A.; Fuentealba, A. Electrocardiographic studies on normal pregnancy. Rev. Med. Chil. 1953, 81, 152-159.

49. Wenger, N.K.; Hurst, J.W.; Strozier, V.N. Electrocardiographic changes in pregnancy. Am. J. Cardiol. 1964, 13, 774-778.

50. Isezuo, S.A.; Ekele, B.A. Eclampsia and abnormal qtc. West Afr. J. Med. 2004, 23, 123-127.

51. Baumert, M.; Seeck, A.; Faber, R.; Nalivaiko, E.; Voss, A. Longitudinal changes in QT interval variability and rate adaptation in pregnancies with normal and abnormal uterine perfusion. Hypertens. Res. 2010, 33, 555-560.

52. Raffaelli, R.; Prioli, M.A.; Parissone, F.; Prati, D.; Carli, M.; Bergamini, C.; Cacici, G.; Balestreri, D.; Vassanelli, C.; Franchi, M. Pre-eclampsia: Evidence of altered ventricular repolarization by standard ECG parameters and qt dispersion. Hypertens. Res. 2014, 37, 984-988.

53. Higham, P.D.; Campbell, R.W. Qt dispersion. Br. Heart J. 1994, 71, 508-510.

54. Bazett, H. An analysis of the time-relations of electrocardiograms. Heart 1920, 7, 353-370.

55. Verdecchia, P.; Schillaci, G.; Borgioni, C.; Ciucci, A.; Gattobigio, R.; Zampi, I.; Porcellati, C. Prognostic value of a new electrocardiographic method for diagnosis of left ventricular hypertrophy in essential hypertension. J. Am. Coll. Cardiol. 1998, 31, 383-390.

56. Prineas, R.; Crow, R.; Blackburn, H. The Minnesota Code Manual of Electrocardiographic Findings: Standards and Procedures for Measurement and Classification; Springer: London, UK, 1982.

57. Tarazi, R.C.; Miller, A.; Frohlich, E.D.; Dustan, H.P. Electrocardiographic changes reflecting left atrial abnormality in hypertension. Circulation 1966, 34, 818-822.

58. Munuswamy, K.; Alpert, M.A.; Martin, R.H.; Whiting, R.B.; Mechlin, N.J. Sensitivity and specificity of commonly used electrocardiographic criteria for left atrial enlargement determined by m-mode echocardiography. Am. J. Cardiol. 1984, 53, 829-832.

59. Lenfant, C. Working group report on high blood pressure in pregnancy. J. Clin. Hypertens. (Greenwich) 2001, 3, 75-88.

60. Lindheimer, M.D.; Taler, S.J.; Cunningham, F.G. Hypertension in pregnancy. J. Am. Soc. Hypertens. 2008, 4, 68-78.

61. Frohlich, E.D.; Tarazi, R.C.; Dustan, H.P. Clinical-physiological correlations in the development of hypertensive heart disease. Circulation 1971, 44, 446-455.

62. Miller, J.T.; O'Rourke, R.A.; Crawford, M.H. Left atrial enlargement: An early sign of hypertensive heart disease. Am. Heart J. 1988, 116, 1048-1051.

63. Bosio, P.M.; McKenna, P.J.; Conroy, R.; O'Herlihy, C. Maternal central hemodynamics in hypertensive disorders of pregnancy. Obstet. Gynecol. 1999, 94, 978-984.

64. Dunn, F.G.; Chandraratna, P.; de Carvalho, J.G.; Basta, L.L.; Frohlich, E.D. Pathophysiologic assessment of hypertensive heart disease with echocardiography. Am. J. Cardiol. 1977, 39, 789-795. 
65. Pearson, A.C.; Gudipati, C.; Nagelhout, D.; Sear, J.; Cohen, J.D.; Labovitz, A.J. Echocardiographic evaluation of cardiac structure and function in elderly subjects with isolated systolic hypertension. J. Am. Coll. Cardiol. 1991, 17, 422-430.

66. Vaziri, S.M.; Larson, M.G.; Lauer, M.S.; Benjamin, E.J.; Levy, D. Influence of blood pressure on left atrial size. The framingham heart study. Hypertension 1995, 25, 1155-1160.

67. Lindheimer, M.D.; Katz, A.I. Sodium and diuretics in pregnancy. N. Engl. J. Med. 1973, 288, 891-894.

68. Myers, B.D.; Peterson, C.; Molina, C.; Tomlanovich, S.J.; Newton, L.D.; Nitkin, R.; Sandler, H.; Murad, F. Role of cardiac atria in the human renal response to changing plasma volume. Am. J. Physiol. 1988, 254, F562-F573.

69. Laragh, J.H.; Atlas, S.A. Atrial natriuretic hormone: A regulator of blood pressure and volume homeostasis. Kidney Int. Suppl. 1988, 25, S64-S71.

70. Lund, C.J.; Donovan, J.C. Blood volume during pregnancy. Significance of plasma and red cell volumes. Am. J. Obstet. Gynecol. 1967, 98, 394-403.

71. Bernstein, I.M.; Ziegler, W.; Badger, G.J. Plasma volume expansion in early pregnancy. Obstet. Gynecol. 2001, 97, 669-672.

72. Nadel, A.S.; Ballermann, B.J.; Anderson, S.; Brenner, B.M. Interrelationships among atrial peptides, renin, and blood volume in pregnant rats. Am. J. Physiol. 1988, 254, R793-R800.

73. Schrier, R.W. Pathogenesis of sodium and water retention in high-output and low-output cardiac failure, nephrotic syndrome, cirrhosis, and pregnancy. N. Engl. J. Med. 1988, 319, 1127-1134.

74. Bond, A.L.; August, P.; Druzin, M.L.; Atlas, S.A.; Sealey, J.E.; Laragh, J.H. Atrial natriuretic factor in normal and hypertensive pregnancy. Am. J. Obstet. Gynecol. 1989, 160, 1112-1116.

75. Mikkelsen, A.L.; Schutten, G.; Asping, U.; Schutten, H.J. Plasma concentration of atrial natriuretic peptide in normal pregnant women and in pregnant women with preeclampsia. Gynecol. Obstet. Investig. 1991, 31, 192-195.

76. Sumioki, H.; Shimokawa, H.; Miyamoto, S.; Uezono, K.; Utsunomiya, T.; Nakano, H. Circadian variations of plasma atrial natriuretic peptide in four types of hypertensive disorder during pregnancy. Br. J. Obstet. Gynaecol. 1989, 96, 922-927.

77. Gerdts, E.; Oikarinen, L.; Palmieri, V.; Otterstad, J.E.; Wachtell, K.; Boman, K.; Dahlof, B.; Devereux, R.B.; Losartan Intervention For Endpoint Reduction in Hypertension, S. Correlates of left atrial size in hypertensive patients with left ventricular hypertrophy: The losartan intervention for endpoint reduction in hypertension (life) study. Hypertension 2002, 39, 739-743.

78. Ingec, M.; Yilmaz, M.; Gundogdu, F. Left atrial mechanical functions in pre-eclampsia. J. Obstet. Gynaecol. Res. 2005, 31, 535-539.

79. Borghi, C.; Esposti, D.D.; Immordino, V.; Cassani, A.; Boschi, S.; Bovicelli, L.; Ambrosioni, E. Relationship of systemic hemodynamics, left ventricular structure and function, and plasma natriuretic peptide concentrations during pregnancy complicated by preeclampsia. Am. J. Obstet. Gynecol. 2000, 183, 140-147.

80. Vazquez Blanco, M.; Grosso, O.; Bellido, C.A.; Iavicoli, O.R.; Berensztein, C.S.; Ruda Vega, H.; Lerman, J. Dimensions of the left ventricle, atrium, and aortic root in pregnancy-induced hypertension. Am. J. Hypertens. 2001, 14, 390-392. 
81. Pritchett, A.M.; Mahoney, D.W.; Jacobsen, S.J.; Rodeheffer, R.J.; Karon, B.L.; Redfield, M.M. Diastolic dysfunction and left atrial volume: A population-based study. J. Am. Coll. Cardiol. 2005, 45, 87-92.

82. Valensise, H.; Novelli, G.P.; Vasapollo, B.; Borzi, M.; Arduini, D.; Galante, A.; Romanini, C. Maternal cardiac systolic and diastolic function: Relationship with uteroplacental resistances. A doppler and echocardiographic longitudinal study. Ultrasound Obstet. Gynecol. 2000, 15, 487-497.

83. Brown, M.A.; Gallery, E.D.; Ross, M.R.; Esber, R.P. Sodium excretion in normal and hypertensive pregnancy: A prospective study. Am. J. Obstet. Gynecol. 1988, 159, 297-307.

84. Hsueh, W.A.; Luetscher, J.A.; Carlson, E.J.; Grislis, G.; Fraze, E.; McHargue, A. Changes in active and inactive renin throughout pregnancy. J. Clin. Endocrinol. Metab. 1982, 54, 1010-1016.

85. Merrill, D.C.; Karoly, M.; Chen, K.; Ferrario, C.M.; Brosnihan, K.B. Angiotensin-(1-7) in normal and preeclamptic pregnancy. Endocrine 2002, 18, 239-245.

86. Assali, N.S.; Westersten, A. Regional flow-pressure relationship in response to angiotensin in the intact dog and sheep. Circ. Res. 1961, 9, 189-193.

87. Gant, N.F.; Worley, R.J.; Everett, R.B.; MacDonald, P.C. Control of vascular responsiveness during human pregnancy. Kidney Int. 1980, 18, 253-258.

88. AbdAlla, S.; Lother, H.; el Massiery, A.; Quitterer, U. Increased AT1 receptor heterodimers in preeclampsia mediate enhanced angiotensin II responsiveness. Nat. Med. 2001, 7, 1003-1009.

89. Acar, K.; Beyazit, Y.; Sucak, A.; Haznedaroglu, I.C.; Aksu, S.; Tuncer, S.; Ozturkkan, D.; Danisman, N.; Purnak, T.; Misirlioglu, M.; et al. Alterations in the "local umbilical cord blood renin-angiotensin system" during pre-eclampsia. Acta Obstet. Gynecol. Scand. 2007, 86, 1193-1199.

90. Benedetto, C.; Marozio, L.; Ciccone, G.; Chieppa, G.; Quaglia, M.; Matullo, G.; Bertola, L.; Guarrera, S.; Carturan, S.; Stratta, P. Synergistic effect of renin-angiotensin system and nitric oxide synthase genes polymorphisms in pre-eclampsia. Acta Obstet. Gynecol. Scand. 2007, 86, 678-682.

91. Brown, M.A.; Reiter, L.; Rodger, A.; Whitworth, J.A. Impaired renin stimulation in pre-eclampsia. Clin. Sci. (Lond.) 1994, 86, 575-581.

92. Brown, M.A.; Wang, J.; Whitworth, J.A. The renin-angiotensin-aldosterone system in pre-eclampsia. Clin. Exp. Hypertens. 1997, 19, 713-726.

93. Herse, F.; Dechend, R.; Harsem, N.K.; Wallukat, G.; Janke, J.; Qadri, F.; Hering, L.; Muller, D.N.; Luft, F.C.; Staff, A.C. Dysregulation of the circulating and tissue-based renin-angiotensin system in preeclampsia. Hypertension 2007, 49, 604-611.

94. Mistry, H.D.; Kurlak, L.O.; Broughton Pipkin, F. The placental renin-angiotensin system and oxidative stress in pre-eclampsia. Placenta 2013, 34, 182-186.

95. Pedersen, E.B.; Rasmussen, A.B.; Johannesen, P.; Kornerup, H.J.; Kristensen, S.; Lauritsen, J.G.; Wohlert, M. The renin-aldosterone system in pre-eclampsia, essential and transient hypertension during pregnancy, and normotensive pregnant and non-pregnant control subjects. Acta Endocrinol. (Cph.) 1982, 101, 273-280.

96. Raty, R.; Koskinen, P.; Alanen, A.; Irjala, K.; Matinlauri, I.; Ekblad, U. Prediction of pre-eclampsia with maternal mid-trimester total renin, inhibin A, AFP and free $\beta$-hCG levels. Prenat. Diagn. 1999, 19, 122-127. 
97. Verdonk, K.; Visser, W.; van den Meiracker, A.H.; Danser, A.H. The renin-angiotensin-aldosterone system in pre-eclampsia: The delicate balance between good and bad. Clin. Sci. (Lond.) 2014, 126, 537-544.

98. Mazzolai, L.; Nussberger, J.; Aubert, J.F.; Brunner, D.B.; Gabbiani, G.; Brunner, H.R.; Pedrazzini, T. Blood pressure-independent cardiac hypertrophy induced by locally activated renin-angiotensin system. Hypertension 1998, 31, 1324-1330.

99. Hein, L.; Stevens, M.E.; Barsh, G.S.; Pratt, R.E.; Kobilka, B.K.; Dzau, V.J. Overexpression of angiotensin at 1 receptor transgene in the mouse myocardium produces a lethal phenotype associated with myocyte hyperplasia and heart block. Proc. Natl. Acad. Sci. USA 1997, 94, 6391-6396.

100. Briceno-Perez, C.; Briceno-Sanabria, L.; Vigil-de Gracia, P. Prediction and prevention of preeclampsia. Hypertens. Pregnancy 2009, 28, 138-155.

101. Cnossen, J.S.; ter Riet, G.; Mol, B.W.; van der Post, J.A.; Leeflang, M.M.; Meads, C.A.; Hyde, C.; Khan, K.S. Are tests for predicting pre-eclampsia good enough to make screening viable? A review of reviews and critical appraisal. Acta Obstet. Gynecol. Scand. 2009, 88, 758-765.

102. Conde-Agudelo, A.; Villar, J.; Lindheimer, M. World health organization systematic review of screening tests for preeclampsia. Obstet. Gynecol. 2004, 104, 1367-1391.

103. Meads, C.A.; Cnossen, J.S.; Meher, S.; Juarez-Garcia, A.; ter Riet, G.; Duley, L.; Roberts, T.E.; Mol, B.W.; van der Post, J.A.; Leeflang, M.M.; et al. Methods of prediction and prevention of pre-eclampsia: Systematic reviews of accuracy and effectiveness literature with economic modelling. Health Technol. Assess. 2008, 12, 1-270.

104. Powers, R.W.; Catov, J.M.; Bodnar, L.M.; Gallaher, M.J.; Lain, K.Y.; Roberts, J.M. Evidence of endothelial dysfunction in preeclampsia and risk of adverse pregnancy outcome. Reprod. Sci. 2008, 15, 374-381.

105. Redman, C.W.; Sacks, G.P.; Sargent, I.L. Preeclampsia: An excessive maternal inflammatory response to pregnancy. Am. J. Obstet. Gynecol. 1999, 180, 499-506.

106. Roberts, J.M. Endothelial dysfunction in preeclampsia. Semin. Reprod. Endocrinol. 1998, 16, 5-15.

107. Ridker, P.M.; Hennekens, C.H.; Buring, J.E.; Rifai, N. $C$-reactive protein and other markers of inflammation in the prediction of cardiovascular disease in women. N. Engl. J. Med. 2000, 342, 836-843.

108. Wolf, M.; Kettyle, E.; Sandler, L.; Ecker, J.L.; Roberts, J.; Thadhani, R. Obesity and preeclampsia: The potential role of inflammation. Obstet. Gynecol. 2001, 98, 757-762.

(C) 2015 by the authors; licensee MDPI, Basel, Switzerland. This article is an open access article distributed under the terms and conditions of the Creative Commons Attribution license (http://creativecommons.org/licenses/by/4.0/). 